\title{
Dyslipidemia in adolescents and young adults with type 1 and type 2 diabetes: a retrospective analysis
}

Grace Kim ${ }^{1 *}$ (D), Daniel DeSalvo ${ }^{1}$, Danielle Guffey², Charles G. Minard ${ }^{2}$, Constance Cephus ${ }^{3}$, Douglas Moodie ${ }^{3}$ and Sarah Lyons ${ }^{1}$

\begin{abstract}
Background: Youth onset type 1 diabetes (T1D) and type 2 diabetes (T2D) is increasing and associated with earlier vascular complications and mortality. Dyslipidemia is an important modifiable cardiovascular (CVD) risk factor that is under-recognized and undertreated in youth with T1D and T2D. Given this, we evaluated the prevalence and associations between lipid concentrations and clinical CVD risk factors in youth with T1D compared to T2D at our large ethnically diverse diabetes center.

Methods: A retrospective chart review was performed, evaluating patients with T1D or T2D seen at least once in clinic from 2015 to 2017, age 10-22 years of age, duration of diabetes at least 6 months on the date of most recent LDL-cholesterol (LDL-C) concentration, and not on statin therapy. We performed independent and multivariable linear regressions of $\mathrm{LDL}-\mathrm{C}$ and $\mathrm{HDL}$-cholesterol $(\mathrm{HDL}-\mathrm{C})$ concentrations.

Results: There were $32.7 \%$ with T1D $(n=1701)$ and $47.7 \%$ with T2D $(n=298)$ with LDL-C above recommend goal $(\geq 100 \mathrm{mg} / \mathrm{dL} / 2.6 \mathrm{mmol} / \mathrm{L})$. Furthermore, there were $9 \%$ with T1D and $16.4 \%$ with T2D with $\mathrm{LDL} \geq 130 \mathrm{mg} / \mathrm{dL}(\geq 3.4$ $\mathrm{mmol} / \mathrm{L}$ ), who likely met criteria for starting statin therapy. Higher LDL-C and/or lower HDL-C were associated with increased age, diabetes duration, higher HbA1C, female sex, Hispanic ethnicity, obesity, and T2D. After adjusting for these risk factors in a multivariable linear regression model, the association of higher LDL-C and lower HDL-C was higher with T2D than T1D.
\end{abstract}

Conclusions: This highlights the need for more aggressive dyslipidemia screening and treatment in youth with diabetes, especially T2D. At our institution we have created and instituted quality improvement algorithms to try to address this need.

Keywords: Dyslipidemia, Type 1 diabetes, Type 2 diabetes, LDL cholesterol, HDL cholesterol

\footnotetext{
* Correspondence: Grace.Kim@bcm.edu

'Department of Pediatrics, Section of Diabetes and Endocrinology, Texas Children's Hospital, Baylor College of Medicine, Houston, TX 77030, USA

Full list of author information is available at the end of the article
}

(c) The Author(s). 2020 Open Access This article is licensed under a Creative Commons Attribution 4.0 International License, which permits use, sharing, adaptation, distribution and reproduction in any medium or format, as long as you give appropriate credit to the original author(s) and the source, provide a link to the Creative Commons licence, and indicate if changes were made. The images or other third party material in this article are included in the article's Creative Commons. licence, unless indicated otherwise in a credit line to the material. If material is not included in the article's Creative Commons licence and your intended use is not permitted by statutory regulation or exceeds the permitted use, you will need to obtain permission directly from the copyright holder. To view a copy of this licence, visit http://creativecommons.org/licenses/by/4.0/ The Creative Commons Public Domain Dedication waiver (http://creativecommons.org/publicdomain/zero/1.0/) applies to the data made available in this article, unless otherwise stated in a credit line to the data. 


\section{Background}

Cardiovascular disease (CVD) is a major cause of morbidity and mortality in those with type 1 and type 2 diabetes [1-3]. Youth onset type 1 diabetes (T1D) and type 2 diabetes (T2D) is increasing in prevalence and associated with early atherosclerosis, CVD risk factors, vascular complications, and mortality [4-9]. Youth onset T2D compared to youth onset T1D is associated with earlier diabetes related complications, increased CVD risk factors, and increased mortality [10-13]. These underline the importance of screening for and treating CVD risk factors in all youth with both T1D and T2D.

Dyslipidemia is an important modifiable CVD risk factor. Evidence-based recommendations from The International Society for Pediatric and Adolescent Diabetes (ISPAD) and American Diabetes Association (ADA) recommend goal low density lipoprotein cholesterol (LDLC) of $<100 \mathrm{mg} / \mathrm{dL}(2.6 \mathrm{mmol} / \mathrm{L})$ in youth with diabetes $[14,15]$. For pediatric patients above age 10 years of age with elevated LDL-C despite medical nutrition therapy and lifestyle intervention, the guidelines recommend consideration of statin pharmacotherapy based on the severity of LDL-C concentrations and presence of cardiovascular risk factors. However, dyslipidemia is underrecognized and undertreated in youth with diabetes, as a substantial proportion of youth are not meeting recommended guidelines [16-18].

As incidence of youth onset T1D and T2D have been increasing across many ethnic minorities, it is important to look at trends among the ethnically diverse populations $[19,20]$. Given this, we evaluated the prevalence of dyslipidemia in youth with diabetes at our large ethnically diverse pediatric diabetes care center with a high Hispanic population. We also evaluated for associations between lipid concentrations and CVD risk factors in those with T1D and T2D, and we analyzed for differences in presence of modifiable CVD risk factors between T1D and T2D with LDL-C not at ADA/ISPAD goal $(<100 \mathrm{mg} / \mathrm{dL} /<2.6 \mathrm{mmol} / \mathrm{L})$. Our hypotheses were: 1) a majority of the population would have elevated LDL-C concentrations not at goal, 2) higher LDL-C concentrations and lower HDL-C concentrations would be associated with T2D than T1D after adjusting for risk factors, 3) those with LDL-C not at goal, that T2D would be associated with more modifiable cardiovascular risk factors than $\mathrm{T} 1 \mathrm{D}$.

\section{Methods}

\section{Protocol and measurements}

Baylor College of Medicine's Institutional Review Board approved this retrospective chart review. Patient characteristics and clinical and laboratory data were extracted from Texas Children's Hospital's ( $\mathrm{TCH}$ ) electronic medical records (EMR) using Epic Population Health
Registry. Variables included age, sex, race/ethnicity, last hemoglobin A1C (HbA1C), body mass index (BMI), diabetes duration, insulin modality [pump therapy, multiple daily injections (insulin to carbohydrate ratio and correction factor), fixed doses, other], hypertension, and tobacco use. We were unable to assess exercise and family history of CVD due to limitations in the electronic medical records. TCH Diabetes Population Health Registry is an institutional based registry that collects discrete data from clinical documentation, laboratory reporting, and patient self-reporting. BMI was calculated in Epic using CDC charts from 2000 for age and sex [21], and categorized according to pediatric standards of obese (BMI > 95th\%tile), overweight (BMI 85 to <95th\%tile) and normal (BMI <85th\%tile) [22]. Lipid panel was ordered at provider discretion based on established guidelines, but without a standardized process or protocol in place from TCH Laboratories or Quest Diagnostic Laboratories. Clinic HbA1C was obtained from DCA Vantage $^{\mathrm{TM}}$ Analyzer, Seimens.

\section{Population/subjects}

Inclusion criteria were a diagnosis of T1D or T2D seen in clinic at least once at TCH Diabetes Care Center in Houston, Texas, USA, from December 1, 2015-December 1, 2017 with age 10-22 years of age and duration of diabetes at least 6 months on the date of most recent LDL-C concentration. Individuals with LDL-C concentrations that could not be calculated or directly measured by the lab or not screened, or with prescription for statin therapy at time of most recent LDL-C concentration were excluded.

\section{Data analysis}

Patient and clinical characteristics were summarized using mean with standard deviation, median with 25 th and 75th percentiles, and frequency with percentage. The summary statistics were stratified by diabetes type and compared using two sample t-test, Wilcoxon rank sum test, Fisher's exact test, or Chi-square test.

We analyzed lipid concentrations both continuously and categorically based on recommendations by $\mathrm{Na}$ tional Heart Lung Blood Institute Expert Panel [23]. LDL-C was divided into LDL-C $<100 \mathrm{mg} / \mathrm{dL} \quad(<2.6$ $\mathrm{mmol} / \mathrm{L}), \quad 100-129 \mathrm{mg} / \mathrm{dL}$ (2.6-3.3 mmol/L), 130-159 $\mathrm{mg} / \mathrm{dL}(3.4-4.1 \mathrm{mmol} / \mathrm{L})$, and $\geq 160 \mathrm{mg} / \mathrm{dL}(\geq 4.1 \mathrm{mmol} /$ L); high density lipoprotein cholesterol (HDL-C) was categorized as $\mathrm{HDL}-\mathrm{C}<40 \mathrm{mg} / \mathrm{dL} \quad(<1 \mathrm{mmol} / \mathrm{L})$ and $\mathrm{HDL}-\mathrm{C} \geq 40 \mathrm{mg} / \mathrm{dL}(\geq 1 \mathrm{mmol} / \mathrm{L}) ;$ total cholesterol $(\mathrm{TC})$ was categorized as $\mathrm{TC}<200 \mathrm{mg} / \mathrm{dL}(<5.2 \mathrm{mmol} / \mathrm{L})$ and $\mathrm{TC} \geq 200 \mathrm{mg} / \mathrm{dL}(\geq 5.2 \mathrm{mmol} / \mathrm{L})$; triglycerides $(\mathrm{TG})$ were classified as $\mathrm{TG}<130 \mathrm{mg} / \mathrm{dL}(<1.5 \mathrm{mmol} / \mathrm{L})$ and $\mathrm{TG} \geq$ $130 \mathrm{mg} / \mathrm{dL}(\geq 1.5 \mathrm{mmol} / \mathrm{L})$.

We assessed independent (unadjusted) linear associations of LDL-C and HDL-C concentrations with clinical 
and CVD risk factors of age, sex, race/ethnicity, BMI percentile, diabetes duration, $\mathrm{HbA} 1 \mathrm{C}$, and diabetes type. Significant risk factors were then combined in a multivariable (adjusted) linear model. We also evaluated in a multivariable logistic regression model for LDL-C $\geq 100$ $\mathrm{mg} / \mathrm{dL} \quad(\geq 2.6 \mathrm{mmol} / \mathrm{L})$ and $\mathrm{HDL}-\mathrm{C}<40 \mathrm{mg} / \mathrm{dL} \quad(<1$ $\mathrm{mmol} / \mathrm{L})$. Furthermore, in those with LDL-C not at ADA/ISPAD goal $(<100 \mathrm{mg} / \mathrm{dL} / 2.6 \mathrm{mmol} / \mathrm{L})$, we evaluated the prevalence of modifiable CVD risk factors. Differences were considered statistically significant if $p<$ 0.05. Statistical analyses performed using Stata v 15.1 (StataCorp, College Station, TX, USA).

\section{Results}

Of the 2077 patients that met inclusion criteria, 44 patients were excluded due to having lipid measurements unable to be calculated or not screened and 34 (including 22 with T1D and 12 with T2D) who had current statin prescriptions at time of lipid concentration. Of the 1999 remaining patients, 1701 (85\%) patients had T1D and 298 (15\%) had T2D (Table 1). There was a difference in race and ethnicity between those with T2D and T1D $(p<$ 0.001 ), with a higher percentage of Hispanic White and Non-Hispanic Black in T2D (T2D vs T1D; $57.8 \%$ vs 22.9 , $29.3 \%$ vs $17.2 \%$ respectively) and higher percentage of Non-Hispanic White in T1D (T1D vs T2D; $54.2 \%$ vs $6.8 \%)$. There was also a difference in BMI between T2D and T1D $(p<0.001)$; T2D had higher rate of obesity (T2D vs T1D; $80.1 \%$ vs $16.5 \%$ ), whereas T1D had higher rate of overweight BMI (T1D vs T2D; $22.7 \%$ vs $13.9 \%$ ). In both groups, there were a high percentage of patients who never used tobacco (T1D vs T2D; $70.9 \%$ vs $78.5 \%$ ) but also a high percentage of patients who were not asked (T1D vs T2D; 27.7 vs $19.5 \%$ ).

Summary statistics for cholesterol concentrations are summarized in Table 2. T2D had higher median LDL-C, lower median HDL-C, higher median TC, and higher median TG. There were 556/1701 (32.7\%) with T1D and $142 / 298(47.7 \%)$ with T2D not at ADA/ISPAD LDL-C goal $(<100 \mathrm{mg} / \mathrm{dL}$ or $2.6 \mathrm{mmol} / \mathrm{L})$. Of those with LDL-C above ADA/ISPAD goal, 153/1701 (9\%) with T1D and 49/298 (16.4\%) with T2D had LDL-C $\geq 130 \mathrm{mg} / \mathrm{dl}(\geq 3.4$ $\mathrm{mmol} / \mathrm{L})$.

Higher LDL-C was independently associated with increased age, diabetes duration, and HbA1C, Hispanic ethnicity, female sex, overweight and obesity, and T2D than T1D (Table 3). After adjusting for age, sex, race/ ethnicity, BMI, diabetes duration, and $\mathrm{HbA} 1 \mathrm{C}$ in a multivariable analysis, the association of increased LDL-C was higher with T2D than T1D $(p=0.005)$ (Table 4).

Lower HDL-C was independently associated with increased age, Hispanic ethnicity, female sex, overweight and obesity, and T2D than T1D (Table 5). Increased diabetes duration and $\mathrm{HbA1C}$ were each associated with
Table 1 Clinical Characteristics in T1D and T2D

\begin{tabular}{|c|c|c|c|}
\hline & T1D & $\mathrm{T} 2 \mathrm{D}$ & $\begin{array}{l}\mathrm{p}- \\
\text { value }\end{array}$ \\
\hline & $\begin{array}{l}N \text { total }= \\
1701\end{array}$ & $\begin{array}{l}N \text { total }= \\
298\end{array}$ & \\
\hline Age, yrs (mean + SD) & $15.4 \pm 2.8$ & $16.2 \pm 2.1$ & $<0.001$ \\
\hline HbA1C, \% (mean \pm SD) & $9 \pm 1.9$ & $8.4 \pm 2.7$ & $<0.001$ \\
\hline $\begin{array}{l}\text { Duration diabetes, years (median, } \\
\text { IQR) }\end{array}$ & $6(3.2,9.1)$ & $\begin{array}{l}2.5(1.5 \\
4.7)\end{array}$ & $<0.001$ \\
\hline Sex, N N (\%) & $N=1701$ & $N=298$ & $<0.001$ \\
\hline Female & $875(51.4)$ & $196(65.8)$ & \\
\hline Male & $826(48.6)$ & $102(34.2)$ & \\
\hline Race/Ethnicity, N N (\%) & $N=1667$ & $N=294$ & $<0.001$ \\
\hline Hispanic White & $382(22.9)$ & $170(57.8)$ & \\
\hline Non-Hispanic White & $904(54.2)$ & $20(6.8)$ & \\
\hline Hispanic Black & $6(0.4)$ & $3(1.0)$ & \\
\hline Non-Hispanic Black & $286(17.2)$ & $86(29.3)$ & \\
\hline Hispanic other & $19(1.1)$ & $8(2.7)$ & \\
\hline Non-Hispanic other & $70(4.2)$ & $7(2.4)$ & \\
\hline BMI, N N (\%) & $N=1687$ & $N=296$ & $<0.001$ \\
\hline Normal (BMI < 85\%) & $1025(60.8)$ & $18(6.1)$ & \\
\hline Overweight (BMI 85-94\%) & $383(22.7)$ & $41(13.9)$ & \\
\hline Obese (BMI > 95\%) & $279(16.5)$ & $237(80.1)$ & \\
\hline Insulin modality, N N (\%) & $N=1700$ & $N=298$ & $<0.001$ \\
\hline Multiple daily injections & $723(42.5)$ & $9(3.0)$ & \\
\hline Pump & $720(42.4)$ & $1(0.3)$ & \\
\hline Fixed Dose & $254(14.9)$ & $149(50.0)$ & \\
\hline Other & $3(0.2)$ & $139(46.6)$ & \\
\hline Tobacco Use, N N (\%) & $N=1701$ & $N=298$ & 0.003 \\
\hline Yes (past or present) & $25(1.4)$ & $6(2)$ & \\
\hline Never & 1205 (70.9) & $234(78.5)$ & \\
\hline Not Asked & $471(27.7)$ & $58(19.5)$ & \\
\hline
\end{tabular}

p-values for mean comparisons performed with t-test

$p$-values for median comparisons using Two-sample Wilcoxon rank-sum (Mann-Whitney) test

$p$-values calculated with exact testing for categorical variables when possible otherwise chi-square test

increased HDL-C. After adjusting for age, sex, race/ethnicity, BMI, diabetes duration, and $\mathrm{HbA} 1 \mathrm{C}$ in a multivariable analysis, the average $\mathrm{HDL}-\mathrm{C}$ was lower among T2D than T1D $(p<0.001)$ (Table 6).

In individuals with LDL-C not at ADA/ISPAD goal, those with T2D had higher rate of obesity (T2D vs T1D; $79.3 \%$ vs $21.5 \%, \mathrm{p}<0.001)$ and HDL-C $<40 \mathrm{mg} / \mathrm{dL}(<1$ $\mathrm{mmol} / \mathrm{L}$ ) (T2D vs T1D; $47.9 \%$ vs $10.6 \%, \mathrm{p}<0.001)$ compared to T1D.

\section{Discussion}

As incidence of youth onset T1D and T2D is increasing and associated with earlier vascular complications and 
Table 2 Lipid Concentrations in T1D and T2D

\begin{tabular}{|c|c|c|c|}
\hline \multirow{3}{*}{$\overline{L D L-C ~(m g / d L) ~}$} & \multirow{2}{*}{$\begin{array}{l}\text { T1D } \\
\mathrm{N} \text { total = } 1701 \\
\mathrm{~N}(\%)\end{array}$} & \multirow{2}{*}{$\begin{array}{l}\text { T2D } \\
N \text { total = } 298 \\
N(\%)\end{array}$} & \multirow[t]{2}{*}{ p-value } \\
\hline & & & \\
\hline & & & $<0.001$ \\
\hline$<100$ & $1145(67.3)$ & $156(52.3)$ & \\
\hline $100-129$ & $403(23.7)$ & $93(31.2)$ & \\
\hline 130-159 & $112(6.6)$ & $38(12.8)$ & \\
\hline$>=160$ & $41(2.4)$ & $11(3.7)$ & \\
\hline Median & $87 \mathrm{mg} / \mathrm{dL}=2.3 \mathrm{mmol} / \mathrm{L}$ & $97.5 \mathrm{mg} / \mathrm{dL}=2.5 \mathrm{mmol} / \mathrm{L}$ & $<0.001$ \\
\hline HDL-C (mg/dL) & & & $<0.001$ \\
\hline$>=40$ & $1532(90.1)$ & $160(53.7)$ & \\
\hline$<40$ & $169(9.9)$ & $138(46.3)$ & \\
\hline Median & $55 \mathrm{mg} / \mathrm{dL}=1.4 \mathrm{mmol} / \mathrm{L}$ & $41 \mathrm{mg} / \mathrm{dL}=1.1 \mathrm{mmol} / \mathrm{L}$ & $<0.001$ \\
\hline Total Cholesterol (mg/dL) & & & 0.250 \\
\hline$<200$ & $1406(82.7)$ & $238(79.9)$ & \\
\hline$>=200$ & $295(17.3)$ & $60(20.1)$ & \\
\hline Median & $165 \mathrm{mg} / \mathrm{dL}=4.3 \mathrm{mmol} / \mathrm{L}$ & $169.5 \mathrm{mg} / \mathrm{dL}=4.4 \mathrm{mmol} / \mathrm{L}$ & 0.026 \\
\hline Triglycerides (mg/dL) & & & $<0.001$ \\
\hline$<130$ & $1305(76.7)$ & $137(46.0)$ & \\
\hline$>=130$ & $396(23.3)$ & $161(54.0)$ & \\
\hline Median & $86 \mathrm{mg} / \mathrm{dL}=1.0 \mathrm{mmol} / \mathrm{L}$ & $140.5 \mathrm{mg} / \mathrm{dL}=1.6 \mathrm{mmol} / \mathrm{L}$ & $<0.001$ \\
\hline
\end{tabular}

p-values calculated with exact testing for categorical variables when possible otherwise chi-square test

mortality, it is important to analyze dyslipidemia prevalence and associations with CVD risk factors between $\mathrm{T} 2 \mathrm{D}$ and T1D in the diverse pediatric population. Our study represents retrospective data from a single large diabetes care center with an ethnically diverse

Table 3 Independent (Unadjusted) Linear Regression for LDL-C

\begin{tabular}{lllll}
\hline & Coefficient & \multicolumn{2}{l}{$95 \%$ Confidence Interval } & p-value \\
\hline Age & 1.26 & 0.81 & 1.71 & $<0.001$ \\
Race/Ethnicity & & & & $<0.001$ \\
Hispanic White & Reference & & & \\
Non-Hispanic White & -5.57 & -8.56 & -2.59 & $<0.001$ \\
Hispanic Black & 17.86 & -0.78 & 36.5 & 0.060 \\
Non-Hispanic Black & 1.05 & -2.67 & 4.78 & 0.578 \\
Hispanic Other & -2.21 & -13.14 & 8.72 & 0.692 \\
Non-Hispanic Other & -0.35 & -7.10 & 6.40 & 0.919 \\
Male & -7.04 & -9.52 & -4.56 & $<0.001$ \\
BMl & & & & $<0.001$ \\
Normal & Reference & & & \\
Overweight & 7.35 & 4.19 & 10.52 & $<0.001$ \\
Obese & 10.13 & 7.18 & 13.09 & $<0.001$ \\
Diabetes Duration & 0.51 & 0.20 & 0.82 & $<0.001$ \\
Hgb A1c & 2.87 & 2.28 & 3.46 & $<0.001$ \\
Type 2 Diabetes & 9.12 & 5.65 & 12.60 & $<0.001$ \\
\hline
\end{tabular}

population, which showed a high percentage of youth with LDL-C not at goal $(<100 \mathrm{mg} / \mathrm{dL} /<2.6 \mathrm{mmol} / \mathrm{L})$ : $32.7 \%(556 / 1701)$ with T1D and $47.7 \%(142 / 298)$ with T2D. Of those that likely met criteria to start statin therapy $(\mathrm{LDL} \geq 130 \mathrm{mg} / \mathrm{dL} / 3.4 \mathrm{mmol} / \mathrm{L})$, there were $9 \%(153 /$

Table 4 Multivariable (Adjusted) Linear Regression for LDL-C

\begin{tabular}{lllll}
\hline & Coefficient & \multicolumn{2}{l}{$95 \%$ Confidence Interval } & p-value \\
\hline Type 2 diabetes & 6.19 & 1.90 & 10.48 & 0.005 \\
Age & 0.82 & 0.34 & 1.30 & 0.001 \\
Male & -6.10 & -8.55 & -3.66 & $<0.001$ \\
Race/Ethnicity & & & & 0.302 \\
Hispanic White & Reference & & & \\
Non-Hispanic White & -0.64 & -3.74 & -2.45 & 0.684 \\
Hispanic Black & 16.83 & -0.96 & 34.61 & 0.064 \\
Non-Hispanic Black & -1.00 & -4.60 & 2.60 & 0.586 \\
Hispanic Other & 1.12 & -9.40 & 11.64 & 0.835 \\
Non-Hispanic Other & 3.99 & -2.58 & 10.56 & 0.234 \\
BMl & & & & $<0.001$ \\
Normal weight & Reference & & & \\
Overweight & 5.18 & 2.03 & 8.32 & 0.001 \\
Obese & 7.05 & 3.65 & 10.46 & $<0.001$ \\
Diabetes Duration & 0.46 & 0.11 & 0.80 & 0.010 \\
Hgb A1c & 2.97 & 2.36 & 3.57 & $<0.001$ \\
\hline
\end{tabular}


Table 5 Independent (Unadjusted) Linear Regression for HDL-C

\begin{tabular}{lllll}
\hline & Coefficient & \multicolumn{2}{l}{$95 \%$ Confidence Interval } & p-value \\
\hline Age & -0.91 & -1.15 & -0.67 & $<0.001$ \\
Race/Ethnicity & & & & $<0.001$ \\
Hispanic White & Reference & & & \\
Non-Hispanic White & 3.83 & 2.24 & 5.41 & $<0.001$ \\
Hispanic Black & 5.83 & -4.06 & 15.73 & 0.248 \\
Non-Hispanic Black & 5.18 & 3.21 & 7.16 & $<0.001$ \\
Hispanic Other & -3.94 & -9.75 & 1.86 & 0.183 \\
Non-Hispanic Other & 5.75 & 2.17 & 9.33 & 0.002 \\
Male & -2.90 & -4.22 & -1.58 & $<0.001$ \\
BMl & & & & $<0.001$ \\
Normal & Reference & & & \\
Overweight & -3.61 & -5.22 & -2.01 & $<0.001$ \\
Obese & -12.31 & -13.81 & -10.81 & $<0.001$ \\
Diabetes Duration & 0.28 & 0.11 & 0.45 & $<0.001$ \\
Hgb A1c & 0.52 & 0.20 & 0.84 & $<0.001$ \\
Type 2 Diabetes & -14.72 & -16.46 & -12.97 & $<0.001$ \\
\hline
\end{tabular}

1701) with T1D and $16.4 \%$ (49/298) with T2D. These numbers slightly underestimate the total population with dyslipidemia at our institution as we excluded those that were already started on statin treatment, and for those whom LDL-C could not be calculated due to elevated TG. However, this prevalence of dyslipidemia in our patient population is lower than we hypothesized but overall comparable to, if not slightly less, than other population studies. In the SEARCH for Diabetes in Youth population, a national multicenter study in the

Table 6 Multivariable (Adjusted) Linear Regression for HDL-C

\begin{tabular}{lllll}
\hline & Coefficient & \multicolumn{2}{l}{$95 \%$ Confidence Interval } & p-value \\
\hline Type 2 diabetes & -10.20 & -12.34 & -8.06 & $<0.001$ \\
Age & -0.79 & -1.03 & -0.55 & $<0.001$ \\
Male & -4.55 & -5.77 & -3.33 & $<0.001$ \\
Race/Ethnicity & & & & $<0.001$ \\
Hispanic White & Reference & & & \\
Non-Hispanic White & -1.39 & -2.93 & 0.16 & 0.078 \\
Hispanic Black & 6.66 & -2.21 & 15.52 & 0.141 \\
Non-Hispanic Black & 3.88 & 2.08 & 5.67 & $<0.001$ \\
Hispanic Other & -5.13 & -10.38 & 0.11 & 0.055 \\
Non-Hispanic Other & 0.28 & -3.00 & 3.55 & 0.869 \\
BMl & & & & $<0.001$ \\
Normal weight & Reference & & & \\
Overweight & -3.58 & -5.14 & -2.01 & $<0.001$ \\
Obese & -9.05 & -10.75 & -7.35 & $<0.001$ \\
Diabetes Duration & 0.05 & -0.12 & 0.22 & 0.582 \\
Hgb A1c & 0.14 & -0.16 & 0.44 & 0.366 \\
\hline
\end{tabular}

United States evaluating children and young adults with diabetes, it was reported in 2006 that $47 \%$ of patients with T1D above age 10 years had LDL $\geq 100 \mathrm{mg} / \mathrm{dL}(>$ $2.6 \mathrm{mmol} / \mathrm{L})$, with $15 \% \geq 130 \mathrm{mg} / \mathrm{dL}(\geq 3.4 \mathrm{mmol} / \mathrm{L})$, and $57 \%$ of those with $\mathrm{T} 2 \mathrm{D}$ had $\mathrm{LDL} \geq 100 \mathrm{mg} / \mathrm{dL}(\geq 2.6$ $\mathrm{mmol} / \mathrm{L})$, with $24 \%$ with $\mathrm{LDL} \geq 130 \mathrm{mg} / \mathrm{dL}(\geq 3.4 \mathrm{mmol} /$ L) [24]. Since then other studies worldwide have shown varying high prevalence of dyslipidemia in the pediatric diabetes population. In 2008, a single center in the UK showed that $38 \%$ of children with T1D had LDL $\geq 100$ $\mathrm{mg} / \mathrm{dL}(\geq 2.6 \mathrm{mmol} / \mathrm{L})$, and $10.8 \%$ with $\mathrm{LDL} \geq 130 \mathrm{mg} / \mathrm{dL}$ $(\geq 3.4 \mathrm{mmol} / \mathrm{L})$ [25]. More recently, in 2015 another study at a center in Brazil, showed high LDL $\geq 100 \mathrm{mg} /$ $\mathrm{dL}$ in $44 \%$ of T1D (age 5-31 years of age), and a study from a center in Turkey in 2017 showed 21\% with high $\mathrm{LDL} \geq 130 \mathrm{mg} / \mathrm{dL}(\geq 3.4 \mathrm{mmol} / \mathrm{l})$ [26]. For type 2 diabetes in youth, a single center in California, USA in 2008 , showed that $39.4 \%$ of youth with T2D had LDL $\geq$ $130 \mathrm{mg} / \mathrm{dL}(\geq 3.4 \mathrm{mmol} / \mathrm{L})$. In 2017 , a study from India showed prevalence of high LDL-C $\geq 100 \mathrm{mg} / \mathrm{dL}(\geq 2.6$ $\mathrm{mmol} / \mathrm{L}$ ) was $64.5 \%$ in youth with T2D [27]. One possibility of our prevalence of dyslipidemia being slightly lower than expected, is the increased attention lately to the high rates of dyslipidemia in pediatric patients with diabetes. Also our screening rate was surprisingly high, $>98 \%$, which leads to early detection and hopefully early discussions about dyslipidemia management. Despite these, the prevalence of dyslipidemia in our diabetes population is still high, which shows the need for improved management of dyslipidemia in pediatric patients with diabetes.

Our study population is an ethnically diverse population with high Hispanic prevalence $(57.8 \%$ of T2D and $22.9 \%$ of T1D), higher than that of the national multicenter SEARCH for Diabetes in Youth population (27.6\% of T2D and $13.0 \%$ of the T1D), or of the NHANES (National Health and Nutrition Examination Survey) adolescent populations [12, 28]. Racial disparities have been reported in both T1D and T2D where minorities compared to Non-Hispanic White tend to have increased CVD risk factors including dyslipidemia, however the relationship and mechanism is unclear and complicated $[7,29,30]$. Our study population with a high Hispanic proportion, showed a high prevalence of dyslipidemia, emphasizing the importance of screening and treating dyslipidemia in these youth.

On further analysis of our study population, higher LDL-C and/or lower HDL-C were independently associated with older age, Hispanic ethnicity, female sex, overweight and obesity, longer diabetes duration, higher HbA1C, and T2D. We chose these risk factors to analyze as they have been associated with dyslipidemia $[5,7,25$, 31-36], and to evaluate if they were also significantly associated in our population. The role of sex in 
dyslipidemia in those with T1D or T2D is varied, where generally sex is not associated with increased CV risk factors in those with diabetes [7], though another study showed that females had higher LDL-C and higher TC [5], while another study showed that males were associated with higher odds of progression of HDL-C [31]. Higher BMI is associated with dyslipidemia in many studies and our study was concordant with this [32-34]. Worsening glycemic control has been associated independently with dyslipidemia in multiple studies [25, 31, 32, 34-36]. Higher duration of diabetes is also typically associated with worsening dyslipidemia [25]. It is interesting that in our study, worsening glycemic control and longer duration of diabetes were associated with increased HDL-C concentrations. One possibility for this association is lower HDL-C was associated with T2D, and T2D was associated with lower duration of diabetes and lower $\mathrm{HbA} 1 \mathrm{C}$ in our population. We did try to evaluate these factors separately in T1D and T2D. In T1D, higher HbA1C was again associated with HDL-C, however duration of diabetes was not significant. In T2D, both factors were not significant, likely due to not enough of a sample size (data not shown).

We then adjusted for the significant risk factors, to evaluate whether higher LDL-C and lower HDL-C would be still be associated with specifically T2D versus T1D, as the prevalence of $\mathrm{T} 2 \mathrm{D}$ is increasing in pediatrics, and known to be associated with earlier microvascular and macrovascular complication $[10,11]$. In our population, after adjusting for age, sex, race/ethnicity, obesity, diabetes duration, and $\mathrm{HbA1C}$, both higher LDL-C and lower HDL-C concentrations were associated T2D than T1D. We found that the type of diabetes, specifically T2D, is associated with higher LDL-C and lower HDL-C even after accounting for the major risk factors that contribute to CVD. Additionally, for patients with LDL-C not at goal, presence of other CVD risk factors of obesity and low HDL-C were associated with T2D than T1D. Our analysis is concordant with recent findings from the national multicenter SEARCH for Diabetes in Youth population, where the prevalence of $\geq 2$ CVD risk factors among youth with T2D was 8-10 times as high as youth with T1D [12]. These are consistent with studies showing youth onset T2D is associated with earlier complications than youth onset T1D or adults with T2D [9-11, 37]. It has been suggested that there are differences in the pathophysiology of dyslipidemia in T2D vs T1D, however this mechanism has not yet been elucidated [38]. Thus, we need to be vigilant with dyslipidemia management in youth onset diabetes, especially T2D.

At our institution, lipid screening was at the discretion of the individual providers, and not based on standardized institutional protocols for screening and ongoing management. This led to limitations of lipid concentrations that were both fasting and non-fasting, leading to a small percentage of LDL-C concentrations that were unable to be calculated due to high triglycerides. Another limitation is that there were high rates of unreported tobacco status. Other cardiovascular risk factors including family history of cardiovascular disease, hypertension, diet history, and exercise were other factors unable to be obtained due to limitations with the electronic health registry. In addition, our results may not be generalizable to the whole population as we present a retrospective chart review of our single tertiary diabetes care center with a high Hispanic population. Also, these findings do not necessarily predict CVD outcomes as we focused on the associations with lipid abnormalities and diabetes. Of note, the pediatric guidelines are extrapolated from adult data, thus in general more long term studies are needed to know the exact long term outcomes of improved dyslipidemia control in pediatric patients with diabetes. Despite the limitations, we had a large diverse population with T1D and T2D for analysis.

\section{Conclusions}

In summary, in our large diabetes care center with an ethnically diverse population, our study showed a high percentage of pediatric patients with T1D and T2D with high LDL-C and low HDL-C concentrations that do not meet recommended LDL-C goals $(<100 \mathrm{mg} / \mathrm{dL} /<2.6$ $\mathrm{mmol} / \mathrm{L}$ ): $32.7 \%$ in T1D and $47.7 \%$ in T2D. Those who likely met criteria to start statin therapy with $\mathrm{LDL} \geq 130$ $\mathrm{mg} / \mathrm{dL}(>3.4 \mathrm{mmol} / \mathrm{L})$, were $9 \%$ in T1D and $16.4 \%$ in T2D. We identified the association of high LDL-C and low HDL-C concentrations was higher with T2D than T1D when adjusting for CVD risk factors. Also, for those with LDL-C not at ADA/ISPAD goal, patients with T2D had more cardiovascular risk factors. These results are not entirely unexpected, but offer more insight into the population we treat at our diabetes care center and emphasize the continued need for rigorous screening and treatment for dyslipidemia in patients with T1D and especially T2D. Improved treatment may include statin therapy, which we noted low rates of statin use in both the T1D and T2D populations at our center. Possible reasons for low rates of statin use include provider comfort with starting statin therapy in pediatric patients, lack of knowledge of guidelines, concern of teratogenicity risk, or lack of acceptance by families.

Based on the knowledge we gained in this study, we initiated a quality improvement initiative at our institution. We are creating a dyslipidemia screening and management (including statin therapy) algorithm, based on evidence based guidelines and risk factors [14, 23]. To alert clinicians of the need to screen, we are creating 
EMR based alerts based on the patient's last LDL-C concentrations and diabetes type. To better educate patients, we are standardizing dietitian education material for dyslipidemia. We will be monitoring if the percentage of LDL-C not at goal is improved based on these targeted quality improvement initiatives.

\section{Abbreviations}

T1D: Type 1 diabetes mellitus; T2D: Type 2 diabetes mellitus; CVD: Cardiovascular disease; ISPAD: International Society of Pediatrics and Adolescent Diabetes; ADA: American Diabetes Association; LDL-C: LDL cholesterol; HDL-C: HDL cholesterol; TC: Total cholesterol; TG: Triglycerides; TCH: Texas Children's Hospital; EMR: Electronic medical records; HbA1C: Hemoglobin A1C; BMl: Body mass index

\section{Acknowledgements}

We would like to thank Fida Bacha, MD, Nidhi Bansal, MBBS, MPH, for helping to review the data, and Rona Sonabend, MD, for data use through Epic Population Health registry.

\section{Authors' contributions}

All authors (GK, SL, DD, DM, CC, DG, CM) were involved in the design and conception of the study, interpretation of the data, revision of the manuscript. GK and SL also obtained IRB approval and drafted the initial manuscript. DG and CM also performed the initial analysis of the data. All authors read and approved the final manuscript.

\section{Author's information}

Not applicable.

\section{Funding}

This research did not receive any specific grant from funding agencies in the public, commercial, or not-for-profit sectors.

\section{Availability of data and materials}

The datasets used and/or analyzed during the current study are available from the corresponding author on reasonable request.

\section{Ethics approval and consent to participate}

This study was reviewed and approved by Institutional Review Board for Baylor College of Medicine. A waiver of consent was approved as this was a retrospective chart review and patient information was de-identified.

\section{Consent for publication}

Not applicable, as no identifiable patient information was used in the manuscript.

\section{Competing interests}

The authors declare that they have no financial and non-financial competing interests.

\section{Author details}

'Department of Pediatrics, Section of Diabetes and Endocrinology, Texas Children's Hospital, Baylor College of Medicine, Houston, TX 77030, USA. ${ }^{2}$ Dan L. Duncan Institute for Clinical and Translational Research, Baylor College of Medicine, Houston, TX 77030, USA. ${ }^{3}$ Department of Pediatrics, Section of Cardiology, Texas Children's Hospital, Baylor College of Medicine, Houston, TX 77030, USA.

Received: 22 January 2020 Accepted: 1 May 2020

Published online: 11 June 2020

\section{References}

1. Buse JB, Ginsberg HN, Bakris GL, et al. Primary prevention of cardiovascular diseases in people with diabetes mellitus a scientific statement from the American Heart Association and the American Diabetes Association. Diabetes Care. 2007;30:162-72. https://doi.org/10.2337/dc07-9917.

2. Laing SP, Swerdlow AJ, Slater SD, Burden AC, Morris A, Waugh NR, Gatling W, Bingley PJ, Patterson CC. Mortality from heart disease in a cohort of
23,000 patients with insulin-treated diabetes. Diabetologia. 2003;46:760-5. https://doi.org/10.1007/s00125-003-1116-6.

3. Rawshani A, Rawshani A, Franzen S, et al. Mortality and cardiovascular disease in type 1 and type 2 diabetes. N Engl J Med. 2017;376(15):1407-18. https://doi.org/10.1056/NEJMoa1608664

4. Shah A, Urbina E. Vascular and endothelial function in youth with type 2 diabetes mellitus. Curr Diab Rep. 2017;17(6). https://doi.org/10.1007/s11892017-0869-0.

5. Krantz JS, Mack WJ, Hodis HN, Liu C-R, Liu C-H, Kaufman FR. Early onset of subclinical atheroscerosis in young persons with type 1 diabetes. J Pediatr. 2004;145:452-7. https://doi.org/10.1016/j.jpeds.2004.06.042.

6. Eltayeb AA, Ahmad F-A, Sayed DM, Osama AM. Subclinical vascular endothelial dysfunctions and myocardial changes with type 1 diabetes mellitus in children and adolescents. Pediatr Cardiol. 2014;35:965-74. https://doi.org/10.1007/s00246-014-0883-9.

7. Rodriguez BL, Fujimoto WY, Mayer-Davis EJ, et al. Prevalence of cardiovascular disease risk factors in U.S. children and adolescents with diabetes: the SEARCH for diabetes in youth study. Diabetes Care. 2006;29(8): 1891-6. https://doi.org/10.2337/dc06-0310.

8. Dabelea D, Mayer-Davis EJ, Saydah S, et al. Prevalence of type 1 and type 2 diabetes among children and adolescents from 2001 to 2009. JAMA. 2014; 311(17):1778-86. https://doi.org/10.1001/jama.2014.3201.

9. TODAY study group. Lipid and inflammatory cardiovascular risk worsens over 3 years in youth with type 2 diabetes. Diabetes Care. 2013;36:1758-64. https://doi.org/10.2337/dc12-2388.

10. Dart AB, Martens PJ, Rigatto C, Brownell MD, Dean HJ, Sellers EA. Earlier onset of complications in youth with type 2 diabetes. Diabetes Care. 2014 37(2):436-43. https://doi.org/10.2337/dc13-0954

11. Dabelea D, Stafford J, Mayer-Davis E, et al. Association of Type 1 diabetes vs type 2 diabetes diagnosed during childhood and adolescence with complications during teenage years and young adulthood. JAMA. 2017; 317(8):825-35. https://doi.org/10.1001/jama.2017.0686.

12. Kim G, Divers J, Fino NF, et al. Trends in Prevalence of Cardiovascular Risk Factors from 2002-2012 among Youth Early in the Course of Type 1 and Type 2 Diabetes. The SEARCH for Diabetes in Youth Study. Pediatr Diab. 2019:pedi.12846. doi:https://doi.org/10.1111/pedi.12846.

13. Constantino MI, Molyneaux L, Limacher-gisler F, et al. Long-term complications and mortality in young-onset diabetes. Diabetes Care. 2013; 36:3863-9. https://doi.org/10.2337/dc12-2455.

14. American Diabetes Association. 13. Children and Adolescents: Standards of Medical Care in Diabetes- 2019. Diabetes Care. 2019;42(Suppl. 1):148-64 https://doi.org/10.2337/dc19-S013.

15. Donaghue KC, Marcovecchio ML, Wadwa RP, et al. ISPAD clinical practice consensus guidelines 2018: microvascular and macrovascular complications in children and adolescents. Pediatr Diabetes. 2018:19(Suppl 27):262-74. https://doi.org/10.1111/pedi.12742.

16. Wood JR, Miller KM, Maahs DM, et al. Most youth with type 1 diabetes in the T1D exchange clinic registry do not meet American Diabetes Association or International Society for Pediatric and Adolescent Diabetes Clinical Guidelines. Diabetes Care. 2013;36:2035-7. https://doi.org/10.2337/dc12-1959.

17. Ahmadizar F, Souverein $\mathrm{P}$, de Boer A Maitland-van der Zee $\mathrm{AH}$. Undertreatment of hypertension and hypercholesterolaemia in children and adolescents with type 1 diabetes: long-term follow-up on time trends in the occurrence of cardiovascular disease, risk factors and medications use. Br J Clin Pharmacol. 2017. https://doi.org/10.1111/bcp.13482.

18. Schwab KO, Doerfer J, Hecker W, et al. Spectrum and prevalence of Atherogenic risk factors in 27,358 children, adolescents, and young adults with type 1 diabetes. Diabetes Care. 2006;29(2):218-25. https://doi.org/10. 2337/diacare.29.02.06.dc05-0724.

19. Mayer-Davis EJ, Lawrence JM, Dabelea D, et al. Incidence trends of type 1 and type 2 diabetes among youths, 2002-2012. N Engl J Med. 2017;376(15): 1419-29. https://doi.org/10.1056/NEJMoa1610187.

20. Menke A, Casagrande S, Cowie CC. Prevalence of diabetes in adolescents aged 12 to 19 years in the United States, 2005-2014. JAMA. 2016:316(3):3445. https://doi.org/10.1001/jama.2016.5394.

21. Kuczmarski R, Ogden CL, Grummer-Strawn LM, et al. CDC growth charts: United States. Adv Data. 2000;314(8):1-27.

22. Barlow SE. Expert Committee Recommendations Regarding the Prevention, Assessment, and Treatment of Child and Adolescent Overweight and Obesity: Summary Report. Pediatrics. 2007;120(Supplement):S164-92. https:// doi.org/10.1542/peds.2007-2329C 
23. Expert panel on integrated guidelines for cardiovascular health and risk reduction in children and adolescents: summary report. Pediatrics. 2011; 128(5):S213-56. doi:https://doi.org/10.1542/peds.2009-2107C.

24. Kershnar AK, Daniels SR, Imperatore G, et al. Lipid abnormalities are prevalent in youth with type 1 and type 2 diabetes: the SEARCH for diabetes in youth study. J Pediatr. 2006;149(3):314-9. https://doi.org/10. 1016/j.jpeds.2006.04.065

25. Edge JA, James $T$, Shine B. Longitudinal screening of serum lipids in children and adolescents with type 1 diabetes in a UK clinic population. Diabet Med. 2008;25(8):942-8. https://doi.org/10.1111/j.1464-5491.2008. 02518.x.

26. Homma TK, Endo CM, Saruhashi T, et al. Dyslipidemia in young patients with type 1 diabetes mellitus. Arch Endocrinol Metab. 2015;59(3):215-9. https://doi.org/10.1590/2359-3997000000040.

27. Amutha A, Pradeepa R, Chella KS, Anjana RM, Unnikrishnan R, Mohan V. Lipid profile in childhood-and youth-onset type 2 diabetes and their association with microvascular complications. J Assoc Physicians India. 2017; 65:42-7.

28. Demmer RT, Zuk AM, Rosenbaum M, Desvarieux M. Prevalence of diagnosed and undiagnosed type 2 diabetes mellitus among US adolescents: results from the continuous NHANES, 1999-2010. Am J Epidemiol. 2013;178(7):1106-13. https://doi.org/10.1093/aje/kwt088.

29. Redondo M, Libman I, Cheng P, et al. Racial/ethnic minority youth with recent-onset type 1 diabetes have poor prognostic factors. Diabetes Care. 2018:41(5):1017-24. https://doi.org/10.2337/dc17-2335.

30. Maahs DM, Daniels SR, De Ferranti SD, et al. Cardiovascular disease risk factors in youth with diabetes mellitus: a scientific statement from the American heart association. Circulation. 2014;130(17):1532-58. https://doi. org/10.1161/CIR.0000000000000094.

31. Shah AS, Maahs DM, Stafford JM, et al. Predictors of dyslipidemia over time in youth with type 1 diabetes: for the SEARCH for diabetes in youth study. Diabetes Care. 2017;40:607-13. https://doi.org/10.2337/dc16-2193.

32. Bulut T, Demirel F, Metin A. The prevalence of dyslipidemia and associated factors in children and adolescents with type 1 diabetes. J Pediatr Endocrinol Metab. 2017;30(2):181-7. https:/doi.org/10.1515/jpem-2016-0111.

33. Redondo MJ, Foster NC, Libman IM, et al. Prevalence of cardiovascular risk factors in youth with type 1 diabetes and elevated body mass index. Acta Diabetol. 2016;53(2):271-7. https://doi.org/10.1007/s00592-015-0785-1.

34. Pelham JH, Hanks L, Aslibekyan S, Dowla S, Ashraf AP. Higher hemoglobin $A 1 C$ and atherogenic lipoprotein profiles in children and adolescents with type 2 diabetes mellitus. J Clin Transl Endocrinol. 2019;15(November 2018): 30-4. https://doi.org/10.1016/j.jcte.2018.11.006.

35. Maahs D, Dabelea D, D'Agostino R, et al. Glucose Control Predicts 2-Year Change in Lipid Profile in Youth with Type 1 Diabetes. J Pediatr. 2013; 162(1). https://doi.org/10.1007/s11103-011-9767-z.Plastid.

36. Petitti DB, N A, C A, et al. Serum lipids and glucose control: the SEARCH for diabetes in youth study. Arch Pediatr Adolesc Med 2007;161(2):159-165. doi: https://doi.org/10.1001/archpedi.161.2.159.

37. Metabolic Contrasts Between Youth and Adults With Impaired Glucose Tolerance or Recently Diagnosed Type 2 Diabetes: I. Observations Using the Hyperglycemic Clamp. RISE Consortium. Diabetes Care. 2018;41(8):17071716. doi: 10.2337/dc18-0244

38. Bjornstad P, Eckel RH. Pathogenesis of lipid disorders in insulin resistance : a brief review. Curr Diab Rep. 2018;18(12):127. https://doi.org/10.1007/s11892018-1101-6.

\section{Publisher's Note}

Springer Nature remains neutral with regard to jurisdictional claims in published maps and institutional affiliations.

Ready to submit your research? Choose BMC and benefit from:

- fast, convenient online submission

- thorough peer review by experienced researchers in your field

- rapid publication on acceptance

- support for research data, including large and complex data types

- gold Open Access which fosters wider collaboration and increased citations

- maximum visibility for your research: over $100 \mathrm{M}$ website views per year

At BMC, research is always in progress.

Learn more biomedcentral.com/submissions 